\title{
Editorials and Views
}

\section{a home of our own}

After being a member of the downtown Boston business community for almost eighty-five years, the National Fire Protection Association is about to move into quarters of its own in the City of Quincy just a few miles south of Boston.

During the period that I have been associated with Fire Technology nearly sixteen years now - NFPA's staff has more than doubled. On more than one occasion, we were forced to seek additional space in our home of many years, the Batterymarch Building. Finally, in 1973 we took up residence at 470 Atlantic Avenue and have since leased additional space at that address as well as at 225 Franklin Street, several blocks away. Once again we had outgrown our accommodations. But when we moved in 1973, we knew that the next move would be into a home of our own. The Association's Board of Directors had already expressed its wish that we investigate the feasibility of acquiring our own building.

After a two-year nationwide search, a 42.5-acre hilltop in Quincy, Massachusetts was selected as the site of NFPA's new home. The Board of Directors, in December of 1977, approved an option agreement to purchase the land. After meeting with homeowners in the area and with the City Council, NFPA exercised its option. Ground was broken on September 21, 1979 , and the building is rapidly nearing completion. Moving day has been set for March 27, 1981.

I had an opportunity to view the building just a few weeks ago, and although work was still going on, I was impressed. The work space conveys a feeling of openness and yet suggests a sense of privacy. The atrium will surely be a showplace, and the Learn Not To Burn Exhibit Center will in- 